Ethiopian Journal of Environmental Studies \& Management 7(6): 686 - 694, 2014.

ISSN:1998-0507

doi: http://dx.doi.org/10.4314/ejesm.v7i6.12

Submitted: August 18, 2014

Accepted: October 20, 2014

\title{
DOMESTIC WATER SOURCES AND ITS HEALTH IMPLICATION IN LAPAI LOCAL GOVERNMENT AREA, NIGER STATE, NIGERIA
}

\author{
KUTA, G.I., ${ }^{1}$ EMIGILATI, M.A., ${ }^{1}$, HASSAN, A.B. ${ }^{1}$ AND ${ }^{*}$ IBRAHIM, I. ${ }^{2}$ \\ ${ }^{1}$ Department of Geography, Federal University of Technology Minna, Niger State, Nigeria \\ ${ }^{2}$ Centre for Preliminary and Extra-Mural Studies Federal University of Technology Minna, Niger \\ State, Nigeria
}

\begin{abstract}
This research work studied the importance of water as a resource that needs to be sustained. From the study, it was realised that poor planning, inadequate funding, insufficient relevant manpower and haphazard implementation of national policy for water supply is responsible for the inadequacy of water both in quantity and quality. The major aim of this study will be to determine ways and means of improving the availability of water in adequate quantity and quality. Data were gathered, collated and analyzed in respect of water supply situation in Lapai Local Government Area of Niger State. The research was carried out through sampling of communities at ward levels. It was realised that a total number of 117 boreholes were found out of which 1 was motorised and 116 were hand-pump. About $41.7 \%$ of the hand-pump boreholes were functional at the time of the survey. It was recommended in the study that planning for water supply facilities, especially at state and local government levels should be comprehensive, and implementation of policies should be guided and strictly followed. In addition, operations and maintenance of water facilities should be handed over to the local communities.
\end{abstract}

Key Words: Water resources, Health, Implication, Locals, Diseases

\section{Introduction}

This research work specifically examines Nigeria's water resources as studied in a part of Niger State, in terms of resource profile and the strategies adopted over the years towards optimal exploitation, management and utilization. The environmental implications of water resource use (by man and nature) were also examined taking into specific account the link to sustainable development. Against this background, the problems militating against effective management of the country's water resources are highlighted. The ultimate objective is to

*Corresponding Author: Ibrahim, I.

Email: shiaku29@gmail.com identify a number of critical factors, which must be taken into account in designing appropriate strategies for sustainable utilization of the nation's water resources.

Water, next to air, is the most important need of man. In spite of the considerable investment of Governments in Nigeria over the years in this essential human requirement, a large population still does not have access to water in adequate quantity and quality. It is estimated that only $48 \%$ of the inhabitants of the urban and semi-urban areas of Nigeria and $39 \%$ of rural areas have access to potable water supply. In spite of these low figures, 
the average delivery to the urban population is only 32 litres per capita per day (EPCD) and that for rural areas is 10 epcd. The quality in most cases is suspect. Various reasons responsible for this situation include amongst others, poor planning, inadequate funding, insufficient relevant manpower, and haphazard implementation of a national policy for water supply.

Niger State has also invested large sums of money beginning with the construction of Bosso Dam in 1945 to the expanded water development programmes such as the new Tagwai Dam in Minna, Kontagora, Suleja, Bida, and New Bussa water schemes and other water supply schemes spread across the State. The present level of supply is still very inadequate.

In Niger State, as in most parts of Nigeria, water resource management and utilization is crucial to the country's efforts toward poverty reduction, economic growth and food security while maintaining sustainable ecological systems. Even after nearly sixty years of water supply development in Nigeria, as much as $43 \%$ of the population still lacks access to safe water, with the situation worse in rural areas (Draft Niger State Water and Sanitation Policy, 2008).

In addition to the growing number of mega cities and increasing sizes of existing large cities, the issue of liquid and solid waste disposed into water bodies continue to receive little or no desired attention. Many sewage plants, where they exist, do not function efficiently. Therefore, this study is aimed at assessing water source and health implications with a view to offer recommendations in the study area.

Lapai Local Government is one of the focal points in Niger State not only because of its proximity to the State Capital, it also houses the State University coupled with its rich agricultural potentials. Bordered to the
North and North-East by Paikoro and Gurara Local Government Areas respectively and to the South by the boundaries of the Federal Capital Territory, Abuja and Kogi State. It covers an area of about 3,730 square kilometres, and its population was estimated to be about 88,172 (1991 Census).

The favourable climatic conditions coupled with the vast gentle slope environment makes it possible for people to settle down within its environs for residential and agricultural purposes. The Local Government experiences both wet and dry seasons, characteristics of a tropical climate. The rainy season starts from April/May to October with heavy downpour in most period of July to September. The mean annual rainfall varies between $1,300 \mathrm{~mm}-1,600 \mathrm{~mm}$. The cold harmattan wind ushers in the dry season between November and February. Extensive fertile land for agricultural uses in addition to River Etswan which provides domestic use as well as agricultural water for irrigation activities. The discharge of waste water from bathroom, laundry, slaughterhouses etc have been used to explain the deterioration of most tropical rivers as they pass through inhabited places (Oluwande et al, 1983). Ibrahim (2013) state that one of the major problem affecting the pipe-borne water availability in Minna metropolis is inadequate budgetary allocation to the water ministry. This problem was found to have culminated in the inability of the ministry to replace the obsolete equipments as well as its inability to embark on new water works.

Benka-Coker and Bafor (1999) in their study of the pollution potential of the Teboga Waste tip in Benin City, Nigeria on the physical and chemical characteristics of the Adjacent Ikpoba River suggested that the leachates have the potential to pollute both surface and underground water. 


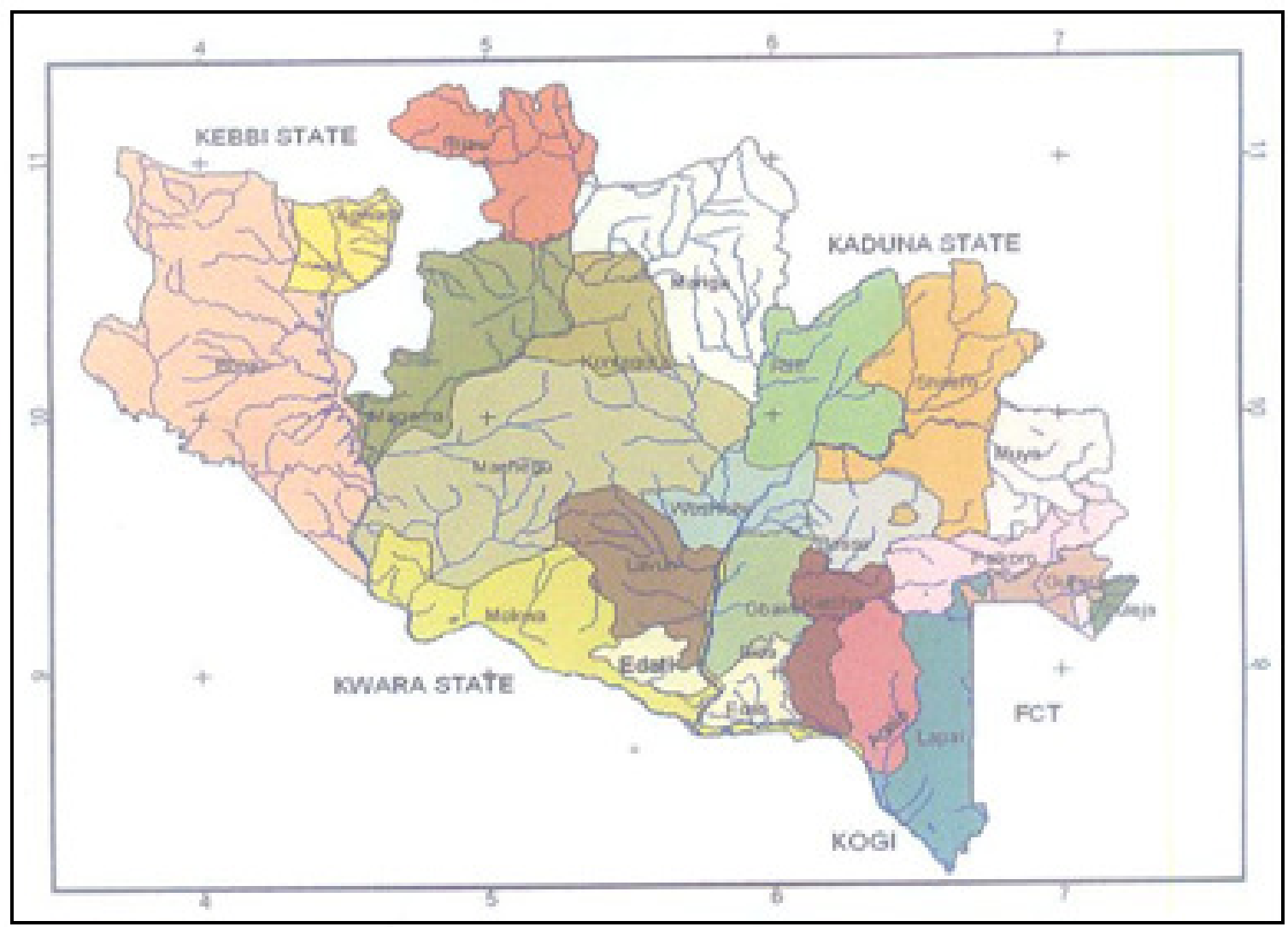

Figure 1: Niger State Drainage Characteristics

\section{Methodology}

In all 10 households in 2 communities each in the 10 wards of the Local Government were questioned which the researchers used as a sample size out of a population of 100 . The total number of people that responded to the questionnaires administered is 20 copies per ward. Also, a survey and manual counting of the existing water facilities if any, was carefully conducted and recorded.

\section{Instrumentation}

In order to obtain information for the realisation of this study, the following instruments were employed:

1. Data Collection: Data used were basically primary data obtained from:

Questionnaire administered to household on water supply and related diseases suffered in 2008.
Field survey carried out by the researchers of the available/existing water facilities in the wards visited.

2. Secondary data obtained from health institutions in the various wards, periodic subject books, journals, and encyclopaedia.

\section{Sampling Procedure Employed}

The cluster of multistage sampling is the one the researchers used in conducting this research. This was employed because the units in the population exist in some natural groups. This type of sampling procedures is such that everyone of the possible cluster in the population has an equal chance of being selected.

The researchers have chosen the cluster or multistage sampling because of its relevance to the topic under study and it is believed to be simpler method of obtaining objectives/data in an investigative research of this nature. 
Statistical Techniques Used in Analysing Data

The simple percentage statistical technique was used in analyzing the tabulated data in respect of the questionnaires administered to respondents. It was also used in analyzing the data collected for the proof of hypothesis.

\section{Discussion of Results}

\section{Sources of Drinking Water}

Figure 2 summarises the obtained from the question: What is your family's main source of drinking water?

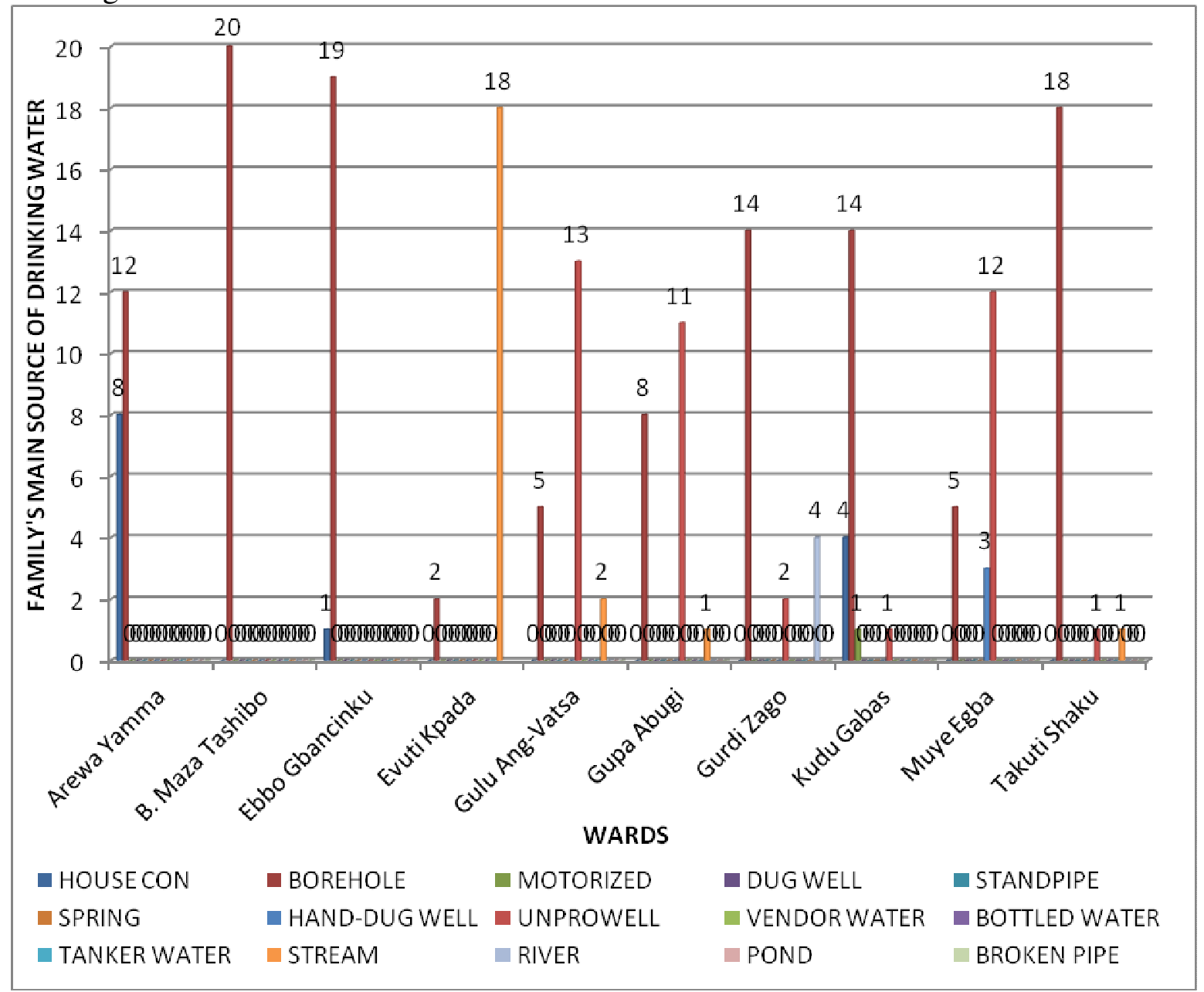

Figure 2: Family Main Source of Drinking Water

From Figure 2, 13 of respondents which represents $6.5 \%$ of the total respondents, get water from connection from pipe borne source, while 117 respondents representing $58.5 \%$ get their water from boreholes, also 1 respondent representing $0.5 \%$ of the respondents get water from motorised boreholes, whereas 3 respondents representing $1.5 \%$ of the respondents get water from hand-dug wells, nevertheless 40 respondents representing $20 \%$ get water from unprotected wells. Maintenance Responsibility

Figure 3 summarizes the results obtained from the question: Who maintains the available water supply facilities? 


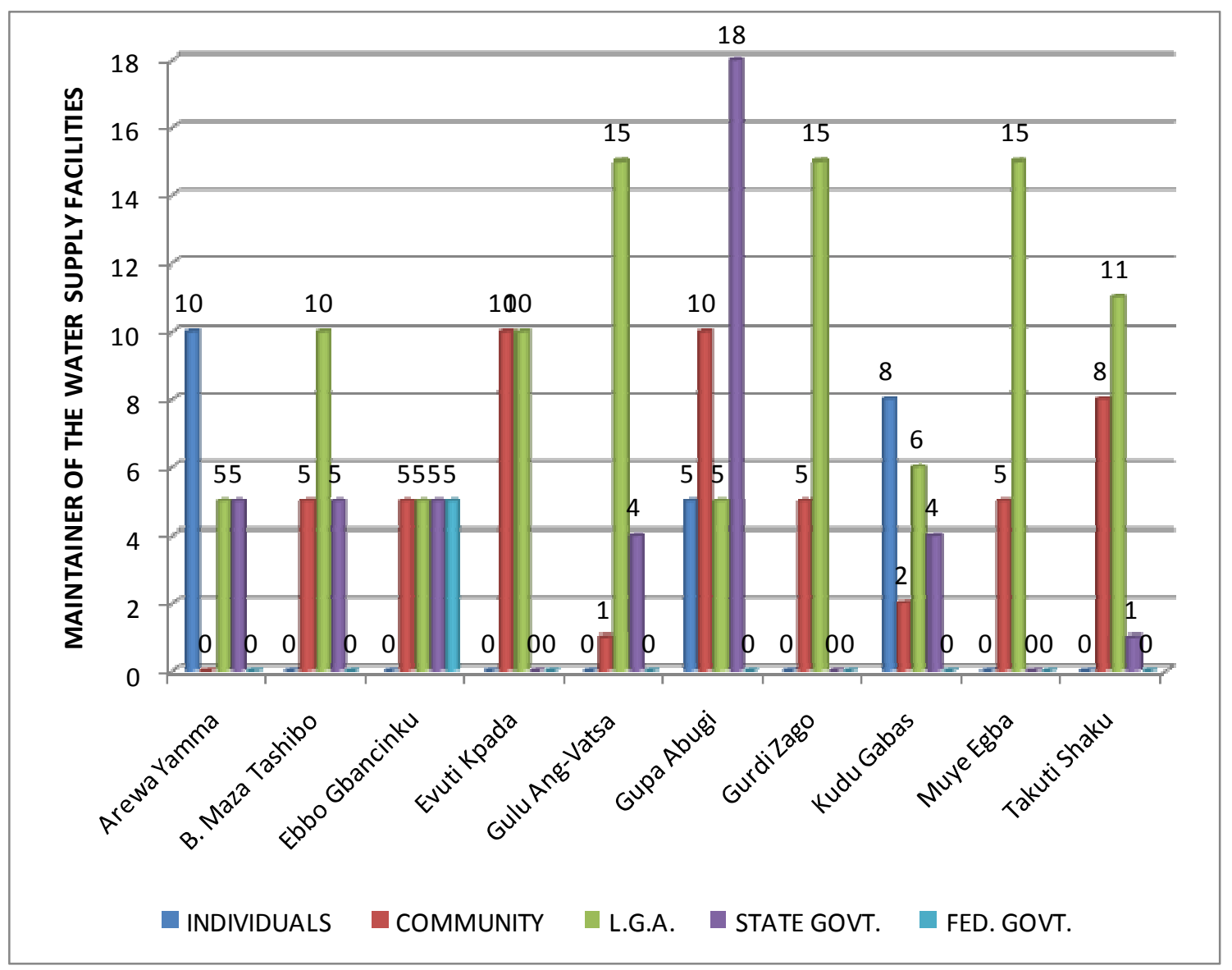

Figure 3: Maintainer of the Water Supply Facilities

From the question in Figure 3, it indicates that $50 \%$ of the available water facilities in Arewa/Yamma ward were maintained by individuals, while $25 \%$ each were maintained by the Local Government and State Government respectively. $25 \%$ of water supply facilities were maintained through communal efforts, $25 \%$ of the facilities were maintained by State Government, whereas the Local Government is responsible for the maintenance of $50 \%$ of water facilities in Maza/Tashibo ward. In Duma/Zago ward, $25 \%$ each of the available water facilities were maintained by the Community, Local Government, State Government and the Federal Government respectively. However, $50 \%$ each of the available water facilities were maintained by the Community and Local Government respectively in
Ebbo/Gbancinku ward. The figure also shows that $5 \%$ of the available water supply facilities were maintained through communal effort, while $75 \%$ were maintained by the Local Government and 20\% were maintained by the State Government respectively in Evuti/Kpada ward. Moreover, in Gulu Angwa/Vatsa, $25 \%$ of the available water facilities were maintained by individuals, $50 \%$ were maintained through communal efforts and $25 \%$ by the Local Government. Maintenance of water facilities in Gupa/Abugi ward was $25 \%$ done through communal effort and $75 \%$ by Local Government. It also shows that in Kudu/Gabas ward, $40 \%$ of available water supply facilities were maintained by individuals, $10 \%$ through communal efforts, $30 \%$ by Local Government and $20 \%$ by State 
Government. In Muye/Egba, 25\% of the available water facilities were maintained through communal efforts and $25 \%$ by the Local Government, while $40 \%$ of the available water supply facilities in
Takuti/Shaku ward were maintained through communal efforts, $55 \%$ by the Local Government and $5 \%$ by the State Government.

\section{Related Water Borne Diseases in Households}

Figure 4 was the summary of the results obtained from the question: Did any member of the household suffer from any water-related borne diseases in 2008 ?

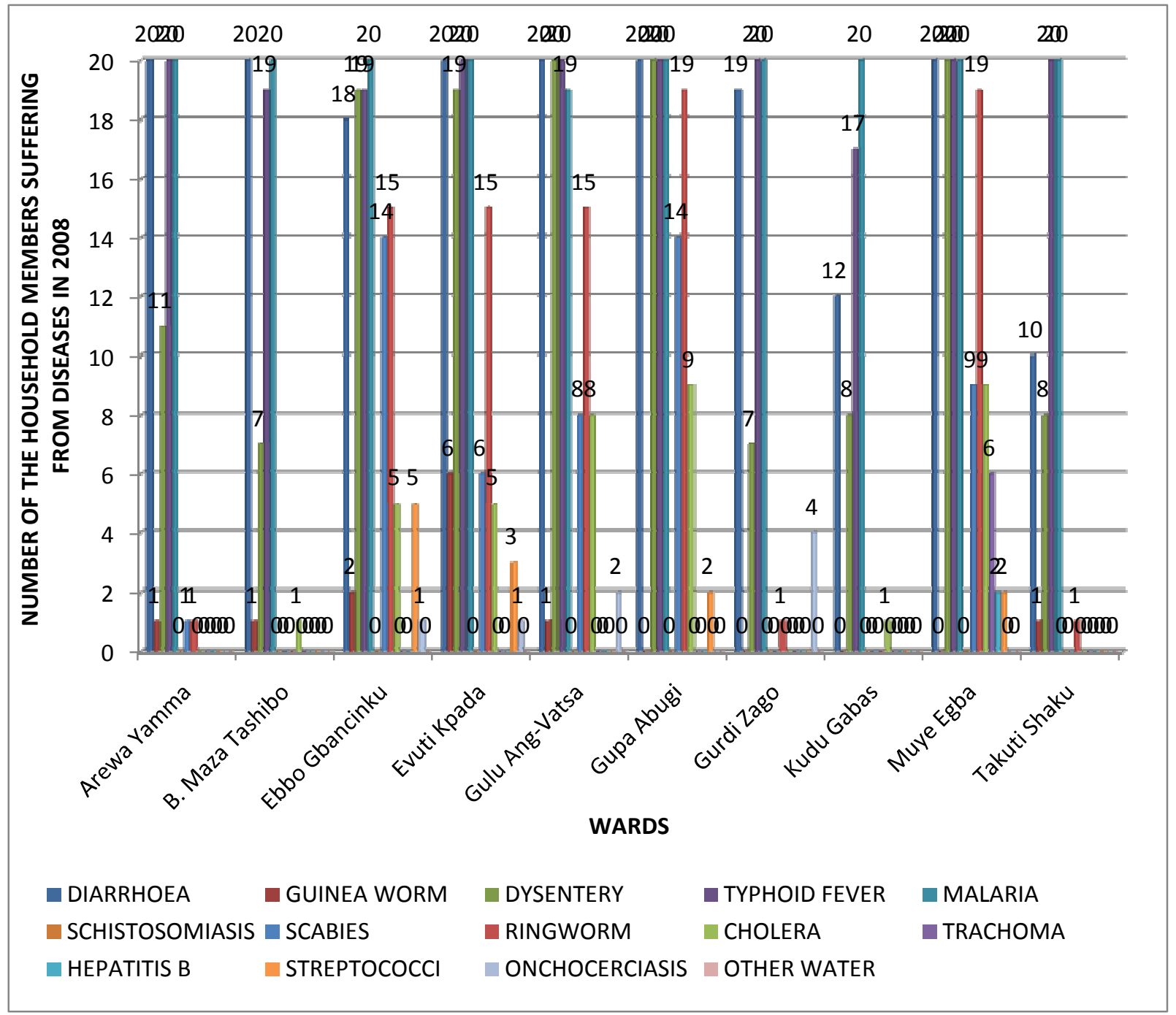

Figure 4: Number of the Household Members Suffering from Diseases in 2008

From the question in Figure 4, 179 of respondents which represents $89.5 \%$ of the total respondents, suffered from diarrhoea in 2008, while 12 respondents representing $6 \%$ of the total respondents suffered from guinea worm in 2008, 139 respondents representing $69.5 \%$ of the respondents suffered from dysentery in 2008, whereas 195 respondents representing $97.5 \%$ of the respondents suffered from typhoid fever in 2008, moreover, 199 respondents representing 
$99.5 \%$ of the respondents suffered from malaria fever, moreover, 52 respondents representing $26 \%$ of the total respondents suffered from scabies in 2008, total number of 86 respondents representing $43 \%$ of the respondents suffered from ringworm in 2008, 38 respondents representing $19 \%$ of the respondents suffered from cholera in 2008, also 6 respondents representing $3 \%$ of the respondents suffered from trachoma, the table also shows that 2 respondents representing $1 \%$ of the respondents suffered from hepatitis B in 2008, it also shows that 12 respondents representing 6\% suffered from streptococci in 2008, and 4 respondents representing $2 \%$ of the total respondents suffered from onchocerciasis in 2008.

\section{Reported Cases of Water Borne Diseases at Ward Level}

Figure 5 was the summary of the results obtained from the question: How many cases of water borne diseases were reported in your health institution in 2008 ?

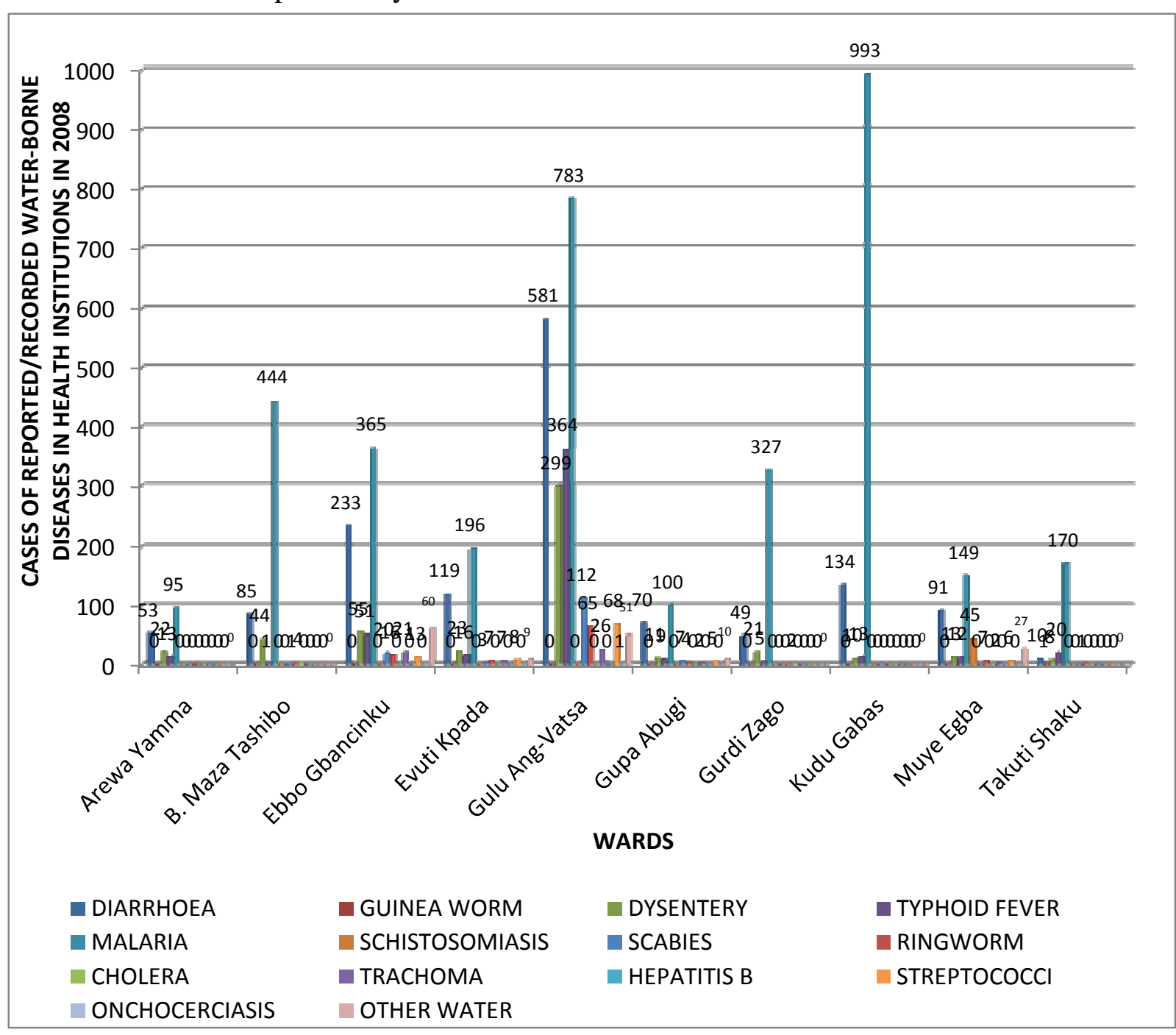

Domestic Water Sources and Its Health Implication in Lapai.

KUTA et al.

Figure 5 indicates that Arewa/Yamma ward has the least record of water borne diseases with a total recorded cases of 185 in 2008, however, Gulu Angwa/Vatsa ward has the highest recorded cases of water borne diseases with a total case of 2,550 in 2008. 


\section{Providers of Water Facilities}

Figure 6 was the summary of the results obtained from the survey of promoters/providers of water facilities in each ward.

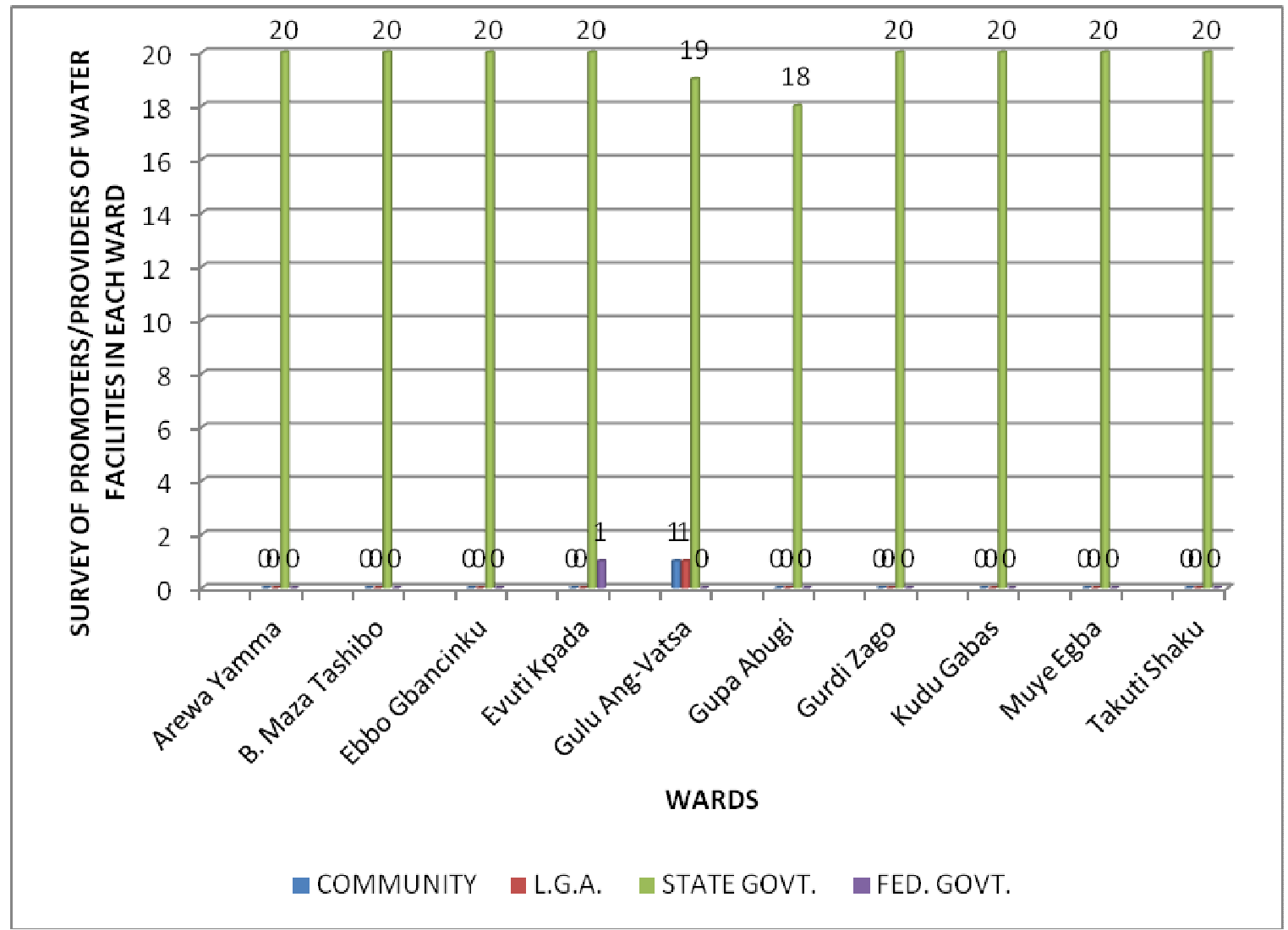

Figure 6: Survey of Promoters/Providers of Water Facilities in Each Ward

Figure 6 indicates that $100 \%$ of water facilities in Arewa/Yamma, Birnin Maza/Tashibo, Duma/Zago, Ebbo/Gbacinku, Gupa/Abugi, Kudu/Gabas, Muye/Egba and Takuti/Shaku ward respectively were solely provided by the State Government, while $90 \%$ of water facilities in Evuti/Kpada ward were provided by the State Government, $5 \%$ are provided by the Federal Government. However, $95 \%$ of the existing water facilities in Gulu Angwa/Vatsa ward were provided by the State Government with $5 \%$ provided by the Federal Government and another 5\% are provided by the community.

\section{Conclusion}

In the course of this paper, it was realised that a total number of 117 boreholes were found out of which 1 is motorised and 116 are hand-pump operated. About $41.7 \%$ of the hand-pump boreholes were functional at the time of the survey.

Meanwhile, the Local Government Authority and State Government share the responsibility for provision and maintenance of water supply facilities. The LGA operates through its Health and Works Departments, while the State Government operates through the State Water Agencies. Other promoters include donor agencies, philanthropists and private commercial promoters who provide water supply facilities.

Thus, they were easily kept in good operational condition. However, to some extent, operation of these facilities is still hampered by factors such as lack of spare parts, and acts of vandalism. 
Most communities within the study area lack access to adequate and safe drinking water; and the condition is exercerbated with prevalence of water related diseases, low physical and economic development which in turn made the communities povertyimpoverished with large number of people fleeing these communities. Viewed from this perspective, it is therefore of enormous importance that a total/integral approach to water resources management be adopted. If these resources are sustained in the right way and manner, it will go a long way in alleviating the suffering of the inhabitants of these communities in particular and the local government as a whole and will improve the standard of livelihood of the citizens and economic status of the State also.

\section{Recommendations}

In the light of the above, the researchers would like to make the following recommendations which, if implemented, will help to solve problems discussed earlier:

- Planning for water supply facilities, especially at State and LGA levels should be comprehensive and articulate.

- Responsibility for operation and maintenance of rural facilities has been successfully transferred to communities in Niger State since the early 1990's. Under the UNICEF/Federal Government intervention between 1987 and 1993, Community Consumer Associations and/or Community Management Organs were established, to whom the boreholes were handed over after commissioning. Local inhabitants were also selected and trained on maintenance of the facilities and spare parts were stocked in the LGA Authority. Currently however, prompt maintenance is hampered by lack of spare parts, the management organs have become ineffective and training of maintenance personnel is not kept up. There is, therefore, an urgent need to re-energize the system.

- Acceptable, affordable and locally maintainable technology has to be established as the key to sustainable facilities. Statistics from the survey show that hand-pump operated boreholes are more versatile than the motorized boreholes.

- Adequate qualified staff at the various operational levels - management, technologists, technicians and craftsmen, supported by other administrative professionals are required. Capacity building and development of appropriate skills by way of training and re-training at all levels of staffing is highly required in the various water agencies.

- A basic minimum of operational support facilities such as workshops, laboratories, hand-tools, transport and offices are also required. Three to four mobile workshops can serve the entire State.

- A pro-active policy or framework on water supply facilities and maintenance should be used as an instrument for resuscitating the water sector of the economy.

- The formulation and implementation of a realistic water supply policy should be adopted.

\section{References}

Benka-Coker, M.O. and Bafor, B.E. (1999). Waste management and water pollution, eds. J.A Pickford, Proceedings of the $25^{\text {th }}$ WEDC conference, pp. 12-16, Addis Ababa.

Draft Niger State Water Supply and Sanitation Policy (2008). First Edition February, 2008, p. 62, 67-68.

Ibrahim, I. (2013). Assessment of the Influence of Population Growth on Pipe-Borne Water Availability in Minna, Nigeria Master Thesis Federal University of Technology, Minna.

Oluwande, P.A., Sridhar, M.K.C., Bammeke, A.O. and Okubadejo, A.O. (1983). Pollution levels in some Nigerian Rivers, Water Research, 17(9): 957963. 